de Abreu, G, Gorgorió, N. \& Boistrup, L. B. (in press) Diversity in mathematics education. In Eds, T. Dreyfus, M. Artigue, D. Potari, S. Prediger, and K. Ruthven, Developments in European Research in Mathematics Education - Twenty Years of Communication, Cooperation and Collaboration. (Routledge).

\title{
Diversity in mathematics education
}

\author{
Guida de Abreu, Núria Gorgorió \& Lisa Björklund Boistrup
}

\section{The emergence and development of a TWG on diversity in mathematics education}

This chapter reviews and reflects the development of the CERME thematic working group on "Diversity in mathematics education." The name of this group has been transformed and extended over the years, as a reflection of the change and expansion of the interests of its members. Thus "Teaching and Learning Mathematics in Multicultural Classrooms" at CERME 3 (proceedings published in 2004) has been progressively transformed into its present name "Diversity in mathematics education: Social, cultural and political challenges." To illustrate this development, this section summarises how the interests of the group have expanded throughout the years.

The centrality of culture in the doing, thinking, learning, and teaching of mathematics has been discussed by many scholars in CERME meetings since they started. Already in the proceedings of CERME 1, before the creation of the group, we find many references that consider several aspects related to culture, from mathematics as a cultural product (Arzarello, Dorier, Hefendehl-Hebeker, \& Turnau, 1999), to mathematical learning as being co-constructed by culture, and to the culture of mathematical classrooms (e.g., Krummheuer, 1999). Similarly, in his keynote address in CERME 1, Jeremy Kilpatrick (1999) pointed out that the increased multi-cultural and multi-lingual composition of many classrooms in many countries called for new research. At the next congress, CERME 2, the challenges associated with multicultural, multi-ethnic, multi-lingual aspects of mathematics education were addressed in several papers, for example Krummheuer (2002) who discussed the challenges in relation to both theory and methods.

Bishop, Clarkson, FitzSimons, and Seah (2002) also contributed to the discussion stressing the importance of values at personal, institutional, social, and cultural levels stating that "at the cultural level, the very sources of knowledge, beliefs, and language, influence our values in mathematics education. Further, different cultures develop different values" (p. 370). Around the same time, the sudden increase in 
levels of migration in many European countries contributed to the visibility of the cultural, ethnic, and linguistic diversities in mathematics classrooms, and several research projects focusing on these issues emerged (e.g., Favilli, Oliveras, \& César's (2004) research in Italy, Spain and Portugal; Gorgorió, Planas \& Vilella's (2002) research in Catalonia; and Alrø, Skovsmose and Valero's (2004) in Denmark). This provided the impetus for the foundation of the TWG "Teaching and Learning Mathematics in Multicultural Classrooms" to become a forum for European researchers involved with the topic area to share, discuss, and reflect on the challenges and types of research being carried out.

One of the key aspects discussed in CERME 3, and which persisted throughout the different meetings, is the realisation that in many European countries, teachers could expect to work with students from ethnic, linguistic, and cultural groups distinct from their own. Cultural, linguistic, political, and social issues, which are often seen as specific to using, teaching, and learning mathematics, for addressing situations where students are from cultures other than those regarded as mainstream have become central to many European classrooms. This has been reflected in papers presented from several European countries, such as Denmark (Alrø, Skovsmose, \& Valero, 2004), Holland (Elbers \& de Haan, 2004), Italy, Spain, and Portugal (Favilli, Oliveras, \& César, 2004), and Germany (Kaiser, 2004). Another key aspect noted early on, was that "multicultural classrooms" were not the only space for research: instead, other settings, and the transitions between those settings, had to be included (e.g., between the school and educational policies, the home mathematical practices, workplaces, etc.). This resulted in a change of the title to "multicultural settings" (CERMEs 4 \& 5; see Abreu, César, Gorgorió, \& Valero, 2006), and of titles that have explicitly included diversity in mathematics education from social, cultural, and political perspectives since CERME 7.

The inclusion of "political perspectives" in the title reflects the interests of researchers presenting their work in this group. Political aspects have been part of the TWG's work from the beginning, and have become a prominent theme in the last four CERMEs. This position rejects the naive idea of research as politically neutral, providing objective data that is used to guide policy making on a supposedly rational basis (Pais, Crafter, Straehler-Pohl, \& Mesquita, 2013; see also Valero, 2013). In CERME 5, an example of this position was introduced by Stentoft (2007) who addressed methodologies of research in multicultural mathematics classrooms from the perspective of power relations between actors in the research. A recent example is Fyhn, Meaney, Nystad, and Nutti (2017) at CERME 10, who addressed culturally responsible teaching of mathematics in relation to indigenous (Sámi) teachers' selfdetermination. Political perspectives focus on how the broader political context of mathematics education (taken in a broad systemic sense, including more than 
mathematics classrooms) affects the teaching and learning of mathematics. Two examples derive from Sweden, where Bagger (2015) addressed the effects of national testing in grade three for students in "special needs" classes, and where Boistrup and Keogh (2017) addressed "workplace mathematics" and institutional norms in a nationwide in-service program.

Political perspectives may also focus on how diversity among learners has consequences in terms of unequal access to the learning of mathematics. This research may include critical investigations of socio-economic backgrounds, among other factors, of students as grounds for unequal mathematics education (e.g., Doğan \& Haser, 2013), where one consequence is the sorting of students due to their socioeconomic backgrounds (e.g., Turvill, 2015). Another focus of research is on examining the tensions between "official discourses" (positing inclusion and equity as fundamental goals) and the actual practices of mathematics teaching (which may actually perpetuate inequities) (Straehler-Pohl \& Pais, 2013).

\section{Meanings attached to diversity in mathematics education}

In the social sciences, it is acknowledged that the challenges which social and cultural diversity poses to education have many facets, and these have been studied from different approaches (Abreu, 2014; Abreu \& Crafter, 2016; De Haan \& Elbers, 2008). Conceptions of the role of the social and the cultural in processes of learning inspire these different approaches, and consequently the different meanings of diversity explored in research. This is also the case for mathematics learning and education.

Thus, despite diversity being of interest to the members of the group, the meanings attached to it have been multiple from the beginning of the group, and remain so. Key meanings of diversity that reflect the patterns of the research presented in CERME include:

- cultural, ethnic, social, and linguistic backgrounds of school students and their school experiences taking into account: a) increased numbers of students with immigrant backgrounds in schools, and classrooms which have changed from mono- to multi-cultural, multi-ethnic, and multi-linguistic composition of the classroom population; and increasing gaps between schools in terms of socioeconomic factors; b) differences in school levels of achievement of students from non-mainstream ethnic, social, economic, and cultural backgrounds (e.g.,. some minority groups achieving significantly lower grades, and sometimes higher grades, than the majority group, as reflected in the education statistics in several countries); c) other forms of student diversity such as gender, level of achievement in school mathematics, and their like or dislike of school mathematics; 
- perspectives and experiences of diversity, taking into consideration teachers' students', and parents' perspectives as well as school / institutional perspectives and policy and political perspectives;

- the focus of discourses used to discuss diversity: a) diversity as a problem; b) diversity as a resource.

A working definition of diversity that includes these aspects was introduced by Valero, Crafter, Gellert, and Gorgorió (CERME 7, 2011), and further elaborated by Boistrup, Meaney, Mesquita, and Straehler-Pohl (CERME 9, 2015). In this definition of diversity, they included:

- diversity of people: of students, teachers, parents, and many other participants in mathematics education - with the diversity even more refracted through aspects such as gender, ethnicity, culture, language, social and socio-economic status, disability, qualification, life opportunities, aspirations, career possibilities, etc., that shape their acting, interacting, valuing and identities, - affected and framed in and by various contexts;

- diversity of contexts which both frame and affect all actors: this includes the formation of policies informing mathematical education, the sites where mathematics education takes place, and the differences in the organisation and structure of practice in such contexts - in schools, homes, workplaces, etc.;

- diversity and possibilities of practice: due to the concrete situations of mathematics education in which multiple diversities may intersect, posing challenges to actual learning and teaching practices, as well as a basis for rethinking what is possible.

This definition of diversity thus includes considerations for research around theoretical approaches to diversity (What is diversity in the context of mathematics education and mathematics education research?), and around the engagement with diversity in educational practice and research (What are the challenges and possibilities emerging from increasing levels of diversity?).

Another key observation is that, despite the multiple sources and perspectives in the study of diversity, this TWG is united in rejecting views and practices of "diversity as a problem" or "diversity as a deficit," and in working towards developing ways of addressing diversity as a resource. The focus on addressing diversity as a resource takes many forms in the group's research. For example, some studies examine the discourses of diversity embedded in the practices and policies of schooling; some studies examine subjective views and experiences of diversity by learners, teachers and parents; and other studies examine the possibilities of new school practices which draw on diversity as a resource. 


\section{How different diversities have been theorised and empirically addressed}

The multiplicity of understandings of diversity also impacts on the way it has been theorised and analysed by TWG participants. It is not only that diversity is polyhedral in itself, but that it can also be seen from different perspectives that make visible particular faces such as the cultural, the social, the political, and the linguistic.

\subsection{Theorizing when researching diversity}

When the group began, the theorizing was dominated by approaches drawing on the cultural nature of mathematics (Bishop, 1988), cultural psychology (Cole, 1996), critical mathematical education (Skovsmose, 2014), and ethnomathematics (D'Ambrosio, 1985). As any one of these approaches was already too broad in itself, while at the same time the number of European researchers working in each area was relatively small, it was difficult at times to foster productive dialogue within the group.

However, over time, despite the different ways of theorizing diversity, it was apparent that the group shared an interest in understanding the key processes in learning and teaching in the context of diversity. These include, for example, an interest in understanding identities (e.g., Abreu, 2006; Black, Solomon, \& Radovic, 2015), agency (e.g., Andersson, \& Norén, 2011), social representations of mathematical knowledge (e.g., Abreu \& Gorgorió, 2007; Gorgorió \& Prat, 2011), cultural representations of mathematical knowledge (e.g., Crafter, 2010; Mukhopadhyay \& Greer, 2015), discourses of diversity (Alrø, Skovsmose, \& Valero, 2006; César \& Favilli, 2006), home and school mathematical practices (Abreu et al., 2006), and transitions between mathematical practices (e.g., Abreu, Crafter, Gorgorió \& Prat, 2013).

This focus on the processes brings some unity to a group that is truly multidisciplinary, and benefits from drawing on and developing a sophisticated theoretical understanding in the field of mathematics education, and social sciences more generally. Focusing especially on the most recent CERMEs, for example CERMEs 7, 8 , and 9, we notice that the theorizing has drawn on a variety of theoretical approaches:

- Socio-cultural psychology - socio-cultural theories of learning and development evolving from Vygotsky and European social representations theory is one family of theoretical approaches informing many studies (e.g., Abreu \& Gorgorió, 2007; Crafter \& Abreu, 2011; Newton \& Abreu, 2011). These also include cultural historical activity theory which is one strand of sociocultural theory that has evolved from the work of Vygotsky (e.g., Gebremichael, Goodchild, \& Nygaard, 
2011), the dialogical self (Abreu et al., 2013; Newton \& Abreu, 2013), and dialogue -drawing on Bakhtin's ideas of dialogism (Rangnes, 2011);

- Discursive and sociological approaches - the notion of discourse in a sociological sense, along with other concepts, has been adopted to explore the social construction of what counts as mathematical knowledge, identity positioning, and issues of equity. For example, Lange and Meaney (2011) examined how public discourse may construct disadvantage; Gellert and Straehler-Pohl (2011) draw on Bernstein's differences between horizontal and vertical discourse, where the concepts of discourse and knowledge are closely interrelated. Johansson and Boistrup (2013) use Bourdieu's concepts habitus and field to investigate signs of mathematical aspects of a person's workplace competence; and Turvill (2015) uses Bourdieu's notions of social and cultural capital to explore the way mathematics education systematically disadvantages particular groups of children;

- Culture and mathematics education - notions from ethnomathematics (e.g., Stathopoulou, François, \& Moreira, 2011; Mukhopadhyay \& Greer, 2015), and critical mathematics education (e.g., Alrø, Skovsmose, \& Valero, 2004, 2006; Hauge et al., 2015) were concerned with the sociopolitical dimension of mathematics education that also informs many studies. Some of the participants based their research within one of these two approaches (e.g., Domite \& Pais, 2010), whereas others sought an articulation between the two (e.g., François \& Pinxten, 2013).

\subsection{Researching diversity}

Similarly, and for the same reasons, the ways diversities have been addressed empirically are multiple. The settings of these studies were varied, including classrooms, schools, communities, institutions, and countries. Within these settings, the focus was on learners, teachers, parents, and professionals from the perspective of the role that various diversities play in the construction of mathematical learning, teaching, practices and uses.

The main way these questions have been pursued was essentially through qualitative approaches (see Seah, Davis, \& Carr, 2017 for an exception), drawing on interpretive frameworks. In many studies, the approach is described as qualitative, with the focus on interpretation. However, other studies clearly situate their approaches within social sciences traditions, including:

- Ethnographic approaches: Ethnography is a popular approach that reflects the shared interest of the group in research that fundamentally aims at uncovering the meanings and experiences of diversity located in socio-cultural contexts. A methodological approach developed by anthropologists as means to understand 
and describe "other cultures," it was adopted by sociologists to investigate cultures perceived as other within western societies, and by social and cultural psychologists to investigate the role of culture and social contexts on psychological functioning. In this way, it is an approach that has been combined with different theoretical approaches (see, e.g., CERME 7 papers by Andersson (2011), Crafter (2011), Díez-Palomar \& Ortin (2011), and Stathopoulou, François, \& Moreira (2011); also CERME 9 papers by Bagger (2015), Parra-Sanchez (2015), and Radovic, Black, Salas, \& Williams (2015)).

- Discourse approaches: Interest in discourse approaches has been increasing in recent years and reflects an interest in a methodological stance that uncovers the social and political constructions of what counts as appropriate mathematical practices, issues of inclusion and exclusion, and processes of identity development and positioning (see, e.g., papers presented in CERME 7 by Andersson \& Norén (2011); Gellert \& Straehler-Pohl (2011); Lange \& Meaney (2011) and the papers presented at CERME 9 by Bagger; Radovic et al. (2015), and Montecino \& Valero (2015)).

- Dialogical and narrative approaches: These approaches are emerging from an interest in understanding the way the person (student, teacher, parent, actors in workplaces, etc.) develops their participation in mathematical practices, and by examining the dialogues between identity positions (associated with different times and past, present, and future identities; different settings, such as home and school; or different roles, such as teacher and parent) (see, e.g., the papers presented at CERME 7 by Abreu, Crafter, Gorgorió, \& Prat (2011); and Newton \& Abreu (2011)).

Within these various research approaches, strategies to collect data have included a variety of methods, such as observations, interviews, questionnaires, and narratives. The review of methods clearly shows a lack of longitudinal studies (an exception is Bagger, 2015) as well as surveys. This confirms the fact that the methods and strategies used not only reflect the users' interpretations of diversity, but also their constructions of its meaning. Moreover, it gives a clear image of how funding (or the lack of it) affects certain research domains.

\section{Conclusions and looking towards the future}

Overall, this review shows that, on a superficial level, there have been times in this TWG when the research presented gave the impression of a collection of papers more like a patchwork than a single united piece. In fact, the difficulty in establishing coherence between the papers presented in the group was noted in several of the coordinators' reports. This retrospective review, however, reveals that, on a deeper 
level, the research presented over these years does reflect a shared common interest in the directions of the theorisation of mathematics learning and the related empirical research; namely, as a human activity and socio-cultural practice located in historical and political contexts.

We suggest that three specific turns unite the research on diversity in mathematics education presented at CERME. The first turn focused on establishing the cultural nature of mathematics knowledge and learning, and it was informed both by ethnomathematical and socio-cultural approaches to mathematical cognition. This resulted in an emphasis on understanding differences in mathematical practices, such as differences between in-school and out-of-school mathematics, and the situated nature of mathematical cognition. One key contribution of this turn was to acknowledge diversity as part of both, with an emphasis on psychological functioning and also an account of the uses and learning of mathematics as socio-culturally and politically located in the context of specific practices. Evidence from research has shown a discontinuity between the ways a person has learned or expressed mathematical competence in school and in their out of school practices. Research has shown that being competent in one practice, such as school mathematics, does not always predict how the individual will perform in another practice (such as in out of school practices). This evidence has been crucial in informing initial studies when the research work focused on multicultural classrooms, and attempted to explore reasons for the barriers in learning experienced by students of immigrant backgrounds without attributing these to any form of individual deficit.

Having achieved a more sophisticated understanding of the cultural diversity of mathematical knowledge, the researchers turned their attention to the social and political aspects of learning. This marks the second turn in the research, and is revealed in the focus on the role of the social and political contexts, such as social interactions, social representations, social institutions, power relationships, public discourses, etc. This added focus moved the understanding of constructions and experiences of diversity forward. Theoretically, this turn resulted in an interest in sociological and socio-psychological perspectives. Thus, as shown in many of the papers presented in the group, social valorisations, and social representations of what counts as school mathematics, embedded in dominant institutional discourses and in practices, may play a key role in the way diversity is experienced. In particular, this turn resulted in exploring the process of mathematical learning in terms of participation in mathematical practices, which involved both the psychological reconstruction of forms of mathematical knowledge and skills (cultural tools), and in terms of constructions of identities. These approaches also highlighted tensions between "official discourses," such as mandated policies and educational practices. A key insight from considering the social and the political is the realisation of the 
possibilities of forms of participation that construct diversities as a resource, and enable experiences of continuity, bridging, dialogue, and negotiation between practices and identities.

The conceptual clarity achieved with the examination of the roles played by the cultural and the social opened the path to a third turn in researching diversity in mathematics education. This third turn focuses on the person as a participant in multiple mathematical practices (Abreu \& Crafter, 2016). This research is interested in exploring the trajectories of participation, and the mediating roles of identities, as they interact in social, cultural, and political contact zones. This includes participation across practices that co-exist in time (e.g., home-school) and over time (schooluniversity, moving countries).

Finally, looking towards the future, we expect that research along the lines summarised above will continue. However, we also expect that new emerging themes will take priority. These could include the ethics of doing research on diversity, the problematisation of diversity and a critical reflection of diversity focused research practices.

The ethics of doing research in relation to diversity of various forms has begun to be addressed (e.g., Eikset et al., 2017). Here, diversity may concern students, children, parents, teachers, classrooms, etc., and may be about culture, achievement, ethnicity, gender, social class, values, histories, or the like. This TWG is united in its striving for social justice, inclusivity, and variety. One consequence of engagement in ethical considerations is reflexivity in research, where the researcher's acts are also critically observed and analysed.

The problematisation of diversity as a concept that is socially constructed is also a key theme that must continue informing research. During CERME 10, diversity as a concept, and the connotations thereof, were problematised (Boistrup, Bohlmann, Diez-Palomar, Kollosche, \& Meaney, 2017; Roos, 2017). One aspect here is that the concept of diversity itself may arise from the assumption that there is something normal from which, for example, diverse students deviate, whereas for this TWG the concept of diversity is likely to be viewed as the norm itself. We expect that there will be more problematisations of diversity as a concept in future CERMEs. A related matter here are words that are similar to diversity, but perhaps carry other connotations such as difference, heterogeneity, multiplicity or variety; also connected words such as democracy, segregation/integration, inclusion/exclusion, or empowerment.

A final key theme that deserves to be addressed is the critical reflection of research practices, including forms of collaboration and methodologies, and the promotion of new and innovative ways of data collection emerging from new technologies and 
means of communication. The group could benefit from collaborative research of a wider dimension which may provide new insights. In relation to this wider dimension, we are thinking, for example, in terms of comparative qualitative case studies across countries, and in terms of longitudinal studies. These combined could contribute to an understanding of the impact of the diversity of educational contexts, and trajectories of development over time, and could incorporate the complementary perspectives of the co-construction of the social, cultural, and political with the psychological.

\section{Acknowledgement}

We are grateful to the feedback from Gail FitzSimons in a previous version of this chapter.

\section{References}

Abreu, G. de, (2006). Cultural identities in the multi-ethnic mathematical classroom. CERME4 (pp. 1131-1140).

Abreu, G. de (2014). Cultural diversity in mathematics education. In S. Lerman (Ed.), Encyclopedia of mathematics education (pp. 125-129). Dordrecht, The Netherlands: Springer.

Abreu, G. de, Crafter, S., Gorgorió, N., \& Prat, M. (2013). Understanding immigrant students' transitions as mathematical learners from a dialogical self-perspective. CERME8 (pp. 1648-1655).

Abreu, G. de, \& Crafter, S. (2016). Mathematics learning in and out of school: Towards continuity or discontinuity? In L. English \& D. Kirshner (Eds.), Handbook of international research in mathematics education (3rd ed.) (pp. 395-415). London, UK: Routledge.

Abreu, G. de, \& Gorgorió, N. (2007). Social representations and multicultural mathematics teaching and learning. CERME5 (pp. 1159-1566).

Abreu, G. de, César, M., Gorgorió, N., \& Valero, P. (2006). Issues and challenges in researching mathematics education in multicultural settings. CERME4 (pp. 1125-1130).

Alrø, H., Skovsmose, O., \& Valero, P. (2004). Communication, conflict and mathematics education in the multicultural classroom. CERME3.

Alrø, H., Skovsmose, O., \& Valero, P. (2006). Culture, diversity and conflict in landscapes of mathematics learning. CERME4 (pp. 1141-1152).

Andersson, A. (2011). Interplays between context and students' achievement of agency. CERME7 (pp. 1399-1408).

Andersson, A., \& Norén, E. (2011). Agency in mathematics education. CERME7 (pp. 1389-1398).

Arzarello, F., Dorier, J-L., Hefendehl-Hebeker, L., \& Turnau, S. (1999). Mathematics as a cultural product. CERME1 (pp. 70-77).

Bagger, A. (2015). Pressures and positions of need during the Swedish third-grade national test in mathematics. CERME9 (pp. 1558-1563).

Bishop, A. J., Clarkson, P., FitzSimons, G., \& Seah, W. T. (2002). Studying values in mathematics education: Aspects of the VAMP Project. CERME2 (pp. 368-376).

Bishop. A. (1988). Mathematical enculturation: A cultural perspective on mathematics education. Dordrecht, The Netherlands: Kluwer.

Black, L., Solomon, Y., \& Radovic, D. (2015). Mathematics as caring: The role of 'others' in a mathematical identity. CERME9 (pp. 1564-1570). 
Boistrup, L. B., Bohlmann, N., Diez-Palomar, J., Kollosche, D., \& Meaney, T. (2017). Introduction to the papers of TWG10: Diversity and mathematics education - social, cultural and political challenges. CERME10.

Boistrup, L., \& Keogh, J. (2017). The context of workplaces as part of mathematics education in vocational studies: Institutional norms and (lack of) authenticity. CERME10.

Boistrup, L. B., Meaney, T., Mesquita, M., \& Straehler-Pohl, H. (2015). Introduction to the papers of TWG10: Diversity and mathematics education - social, cultural and political challenges. CERME9 (pp. 1534-1537).

César, M. \& Favilli, F. (2006). Diversity seen through teachers' eyes: discourses about multicultural classes. CERME4 (pp. 1153-1164)

Cole, M. (1996). Cultural psychology. Cambridge, MA: The Belknap press of Harvard University press.

Crafter, S. (2010). Parental resources for understanding mathematical achievement in multi-ethnic settings. CERME6 (pp. 1453-1461).

Crafter, S., \& Abreu, G. de. (2011). Teachers' discussions about parental use of implicit and explicit mathematics in the home. CERME7 (pp. 1419-1429).

D’Ambrosio, U. (1985). Socio-cultural bases for mathematics education. Campinas, Brasil: Unicamp.

De Haan, M., \& Elbers, E. (2008). Diversity in the construction of modes of collaboration in multiethnic classrooms. In B. van Oers, W. Wardekker, E. Elbers, \& R. van der Veer (Eds.), The transformation of learning: Advances in cultural-historical activity (pp. 219-241). Cambridge, UK: Cambridge University Press.

Díez-Palomar, J., \& Ortin, S. T. (2011). Socio-cultural roots of the attribution process in family mathematics education. CERME7 (pp. 1491-1500).

Domite, M. do C., \& Pais, A. S. (2010). Understanding ethnomathematics from its criticisms and contradictions. CERME6 (pp. 1473-1483).

Doğan, O., \& Haser, Ç. (2013). The gap between mathematics education and low income students' real life: A case from Turkey. CERME8 (pp. 1697-1704).

Eikset, A., Fosse, T., Lange, T., Lie, J., Lossius, M. H., Meaney, T., \& Severina, E. (2017). (Wanting to do) Ethical research in a shifting context. CERME10.

Elbers, E., \& de Haan, M. (2004). The construction of word meaning in a multicultural classroom: Talk and collaboration during mathematics lessons. CERME3.

Favilli, F., Oliveras, M. L., \& César, M. (2004) Maths teachers in multicultural classes: Findings from a Southern European project. CERME3.

Fyhn, A., Meaney, T., Nystad, K., \& Nutti, Y. (2017). How Sámi teachers' development of a teaching unit influences their self-determination. CERME10.

François, F., \& Pinxten, R. (2013). Multimathemacy. CERME8 (pp. 1735-1743).

Gebremichael, A. T., Goodchild, S., \& Nygaard, O. (2011). Students' perceptions about the relevance of mathematics in an Ethiopian preparatory school. CERME7 (pp. 1430-1439).

Gellert, U., \& Straehler-Pohl, H. (2011). Differential access to vertical discourse - managing diversity in a secondary mathematics classroom. CERME7 (pp. 1440-1449).

Gorgorió, N., Planas, N., \& Vilella, X. (2002). Immigrant children learning mathematics in mainstream schools. In G. de Abreu, A. Bishop, \& N. Presmeg (Eds.), Transitions between contexts of mathematical practice (pp. 23-52). Dordrecht, The Netherlands: Kluwer.

Gorgorió, N., \& Prat, M. (2011). Mathematics teachers' social representations and identities made available to immigrant students. CERME7 (pp. 1450-1459).

Hauge, K. H., Sørngård, M. A., Vethe, T. I., Bringeland, T. A., Hagen, A. A., \& Sumstad, M. S. (2015). Critical reflections on temperature change. CERME9 (pp.1577-1583).

Johansson, M. C., \& Boistrup, L. B. (2013). It is a matter of blueness or redness: Adults' mathematics containing competences in work. CERME8 (pp. 1744-1753). 
Kaiser, G. (2004). Learning mathematics within the context of linguistic and cultural diversity: An empirical study. CERME3.

Kilpatrick, J. (1999). Ich bin Europäisch. CERME1 (pp. 49-68).

Krummheuer, G. (1999) Introduction (Social interactions in mathematical learning situations). CERME1 (pp. 305-307).

Krummheuer, G. (2002). The comparative analysis in interpretative classroom research in mathematics education. CERME2 (pp. 339-346).

Lange, T., \& Meaney, T. (2011). Becoming disadvantaged: Public discourse around national testing. CERME7 (pp. 1470-1480).

Montecino, A., \& Valero, P. (2015). Statements and discourses about the mathematics teacher: The research subjectivation. CERME9 (pp. 1617-1623).

Mukhopadhyay, S., \& Greer, B. (2015). Cultural responsiveness and its role in humanizing mathematics education. CERME9 (pp. 1624-1629).

Newton, R., \& Abreu, G. de (2011). Parent-child interactions on primary school-related mathematics. CERME7 (pp. 1481-1490)

Newton, R., \& Abreu, G. de (2013). The dialogical mathematical 'self'. CERME8 (pp. 1784-1791).

Pais, A., Crafter, S., Straehler-Pohl, H., \& Mesquita, M. (2013). Introduction to the papers and posters of WG10: Cultural diversity and mathematics education. CERME8 (pp. 1820-1824).

Parra-Sánchez, A. (2015). Dialogues in ethnomathematics. CERME9 (pp. 1644-1650).

Rangnes, T. E. (2011). Moving between school and company. CERME7 (pp. 1501-1510).

Radovic, D., Black, L., Salas, C., \& Williams, J. (2015). The intersection of girls' mathematics and peer group positionings in a mathematics classroom. CERME9 (pp. 1651-1657).

Roos, H. (2017). Diversity in an inclusive mathematics classroom: A student perspective. CERME10.

Seah, W. T., Davis, E. K., \& Carr, M. (2017). School mathematics education through the eyes of students in Ghana: Extrinsic and intrinsic valuing. CERME10.

Skovsmose, O. (2014). Critical mathematics education. Dordrecht, The Netherlands: Springer.

Stathopoulou, C., François, K., \& Moreira, D. (2011). Ethnomathematics in European context. CERME7 (pp. 1511-1520).

Stentoft, D. (2007). Multiple identities in the mathematics classroom: A theoretical perspective. CERME5 (pp. 1597-1608).

Straehler-Pohl, H., \& Pais, A. (2013). To participate or not participate?: That is not the question! CERME8 (pp. 1794-1803).

Turvill, R. (2015). Number sense as a sorting mechanism in primary mathematics education. CERME9 (pp. 1658-1663).

Valero, P. (2013). Mathematics for all and the promise of a bright future. CERME8 (pp. 1804-1813).

Valero, P., Crafter, S., Gellert, U., \& Gorgorió, N. (2011). Introduction to the papers of WG 10: Discussing diversity in mathematics education from social, cultural and political perspectives. CERME7 (pp. 1386-1388). 